\title{
Successful hybrid surgery for ileal conduit stomal varices following oxaliplatin-based chemotherapy in a patient with advanced colorectal cancer
}

\author{
Hideo Uehara ${ }^{1 *}$, Hirofumi Kawanaka², Tomonori Nakanoko ${ }^{1}$, Masahiko Sugiyama', Mitsuhiko Ota', \\ Yohei Mano ${ }^{3}$, Keishi Sugimachi ${ }^{3}$, Masaru Morita ${ }^{1}$ and Yasushi Toh ${ }^{1}$
}

\begin{abstract}
Background: Ectopic variceal bleeding is a rare but life-threatening complication of portal hypertension (PH). Oxaliplatin-based chemotherapy for colorectal cancer (CRC) is associated with sinusoidal obstruction syndrome of the liver, which can lead to $\mathrm{PH}$.

Case presentation: Here, we report a successful hybrid surgery that included intraoperative obliteration of ileal conduit stomal varices (ICSVS) for a 66-year-old woman with CRC and liver metastasis that had been treated multimodally during the previous 4 years, including 17 courses of oxaliplatin-based chemotherapy. She was admitted to our hospital for massive hemorrhage from an ileal conduct stoma. Image findings showed ICSVs as a part of portosystemic shunt, which were afferently supplied from the superior mesenteric vein (SMV) and drained by the numerous cutaneous veins connected to the left femoral vein. Obliteration of the stomal varices by interventional radiologic techniques alone was inappropriate because of difficulties of cannulating the efferent cutaneous veins. We, therefore, performed hybrid surgery for the ICSV, which included cannulation into the SMV branch and antegrade obliteration of the varices with a $5 \%$ solution of ethanolamine oleate with iopamidol under blocking the SMV flow, using a vascular clip and ligation. Hemorrhage in her ileal conduit stoma disappeared completely.
\end{abstract}

Conclusion: Customized treatment of ectopic varices should be based on their precise vascular anatomy; hybrid surgery with intraoperative angiography is an alternative treatment for ectopic varices such as ICSV.

Keywords: Ectopic varices, Colorectal cancer, Hybrid surgery, Sinusoidal obstruction

\section{Introduction}

Varices are common complications in patients with portal hypertension $(\mathrm{PH})[1-3]$. They are typically located in the esophagus or stomach; varices in other sites, including the duodenum, jejunum, ileum, colon and rectum and stomas, are considered ectopic varices [2]. Ectopic

\footnotetext{
*Correspondence: huehara@surg2.med.kyushu-u.ac.jp

${ }^{1}$ Department of Gastroenterological Surgery, National Hospital Organization Kyushu Cancer Center, Notame 3-1-1, Minami-ku, Fukuoka 811-1395, Japan

Full list of author information is available at the end of the article
}

varices in the small intestine and stoma are usually associated with adhesions of the small or large intestine to the abdominal wall as a result of prior surgeries.

Oxaliplatin-based chemotherapy is a standard treatment for advanced unresectable colorectal cancer (CRC) $[4,5]$. However, as multidisciplinary treatment for CRC has progressed due to the development of surgery, radiotherapy and chemotherapy, survival of patients with CRC has extended, diverse adverse events, such as oxaliplatin-induced liver damage due to sinusoidal obstruction syndrome, have been brought to the surface [6, 7]. Oxaliplatin-based chemotherapy can cause thrombocytopenia, 
splenomegaly or portosystemic collateral vessels as a manifestation of PH. Ectopic variceal bleeding is a serious complication that requires special attention, especially in patients with CRC who have undergone prior surgeries, even those with no history of chronic liver disease.

Managing ectopic variceal bleeding should be decided considering the bleeding site, the cause of bleeding and general condition, which is difficult and still unclear. The treatment of ectopic variceal bleeding requires diverse treatments, including the trans-jugular intrahepatic portosystemic shunt (TIPS) procedure, transhepatic embolization, direct percutaneous embolization, balloon-occluded retrograde transvenous obliteration (BRTO), and other surgeries [8-11]. Here we report a case of ectopic variceal bleeding from an ileal conduit stoma, successfully treated with hybrid surgery that included intraoperative obliteration of the varices and their feeding and drainage veins.

\section{Case report}

A 66-year-old woman was admitted to our hospital for marked hemorrhage in her ileal conduit stoma (Fig. 1). She had previously received many blood transfusions. Eight years before this admission, she had been diagnosed with rectal cancer that had invaded her small intestine, uterus and urinary bladder, and had metastasized to her liver. She underwent a colostomy and intestinal bypass surgery to improve her ileus. After this surgery, she received nine sessions of oxaliplatin-based chemotherapy (mFOLFOX6) plus bevacizumab. We then performed a low anterior resection of her rectum, combined with resections of her uterus, both ovaries, fallopian tubes, and urinary bladder, and a further urinary diversion by ileal conduit. After this second surgery, she underwent

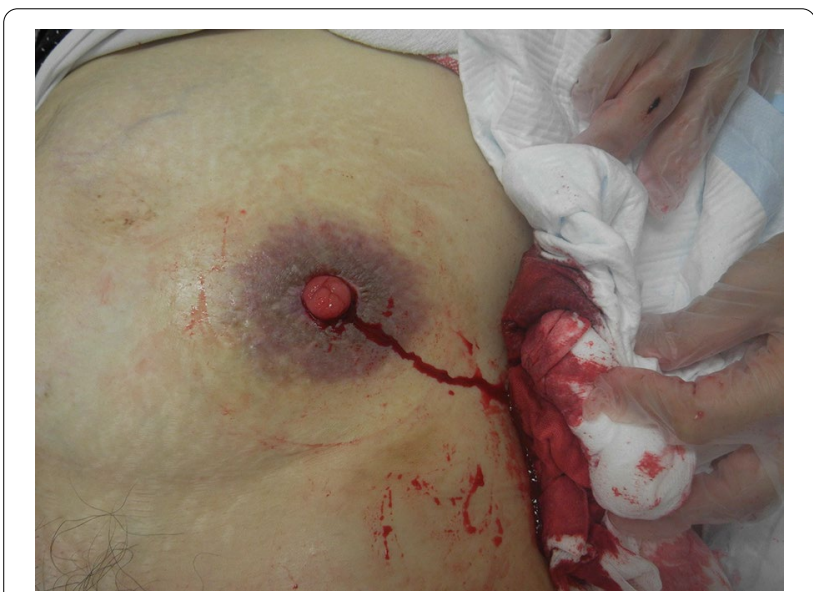

Fig. 1 Ileal conduit stoma with bleeding and purplish peri-stomal discoloration eight cycles of mFOLFOX6 plus bevacizumab. We then performed a partial liver resection, and closure of the colostomy, which was followed by 6 months of adjuvant chemotherapy with capecitabine, after which she had no recurrence for 8 years. However, in the last 4 years, she had been admitted several times for bleeding from her ileal conduit stoma.

On her last admission, she had a Child-Pugh score of 8 (Child-Pugh class B) and her laboratory test results included hemoglobin: $5.6 \mathrm{~g} / \mathrm{dL}$, albumin: $2.4 \mathrm{~g} / \mathrm{dL}$, platelets: $106,000 / \mu \mathrm{L}$, and prothrombin time: $82 \%$. Contrastenhanced computed tomography (CT) showed ileal conduit stomal varices (ICSVs) had developed as a part of the portosystemic shunt, which were supplied from the superior mesenteric vein (SMV) and drained by the numerous cutaneous veins connected to the left femoral vein (Fig. 2). BRTO was not appropriate because of difficulties of cannulating numerous cutaneous veins; and percutaneous transhepatic catheterization has the risks linked to puncturing the portal veins. Therefore, we selected hybrid surgery with intraoperative obliteration for the ICSV.

Under general anesthesia, the patient was placed in a lithotomy position. The skin was incised on the upper and lower abdomen. Adhesions around her small intestine and ileal conduit stoma were very severe. After dissecting a dense peritoneal adhesion, we detected one of the two SMV branches in the ileal conduit mesentery, which were the ICSVs' feeding veins. We tried to measure the portal vein pressure, but the adhesion in the abdominal cavity was severe and it is difficult to cannulate the SMV to the portal vein. We introduced a 4-Fr sheath (Create Medic, Tokyo, Japan) into the vessel (Fig. 3a). As angiography did not initially show sufficient opacification of the stomal varices, we blocked the blood flow of the feeding vein using a proximally placed vascular clip on the SMV. Angiography then showed sufficient opacification of the stomal varices, including the two SMV feeding veins and the numerous cutaneous drainage veins (Fig. 3b). While blocking the afferent blood flow to the stomal varices, we injected a $5 \%$ solution of ethanolamine oleate with iopamidol in an anterograde manner, with sufficiently opacified stomal varices and their feeding and drainage veins; the two SMV branches were then ligated. The lesion was treated with $15 \mathrm{~mL}$ of $5 \%$ solution of ethanolamine oleate with iopamidol.

Seven days after the hybrid surgery, CT showed that the ICSV had disappeared, and the feeding and drainage veins were occluded (Fig. 4), but partial portal vein thrombosis had developed in the SMV. We administered anticoagulation therapy with antithrombin-III concentrates and danaparoid sodium [12, 13], and that portal vein thrombosis disappeared by 14 days after the surgery. 

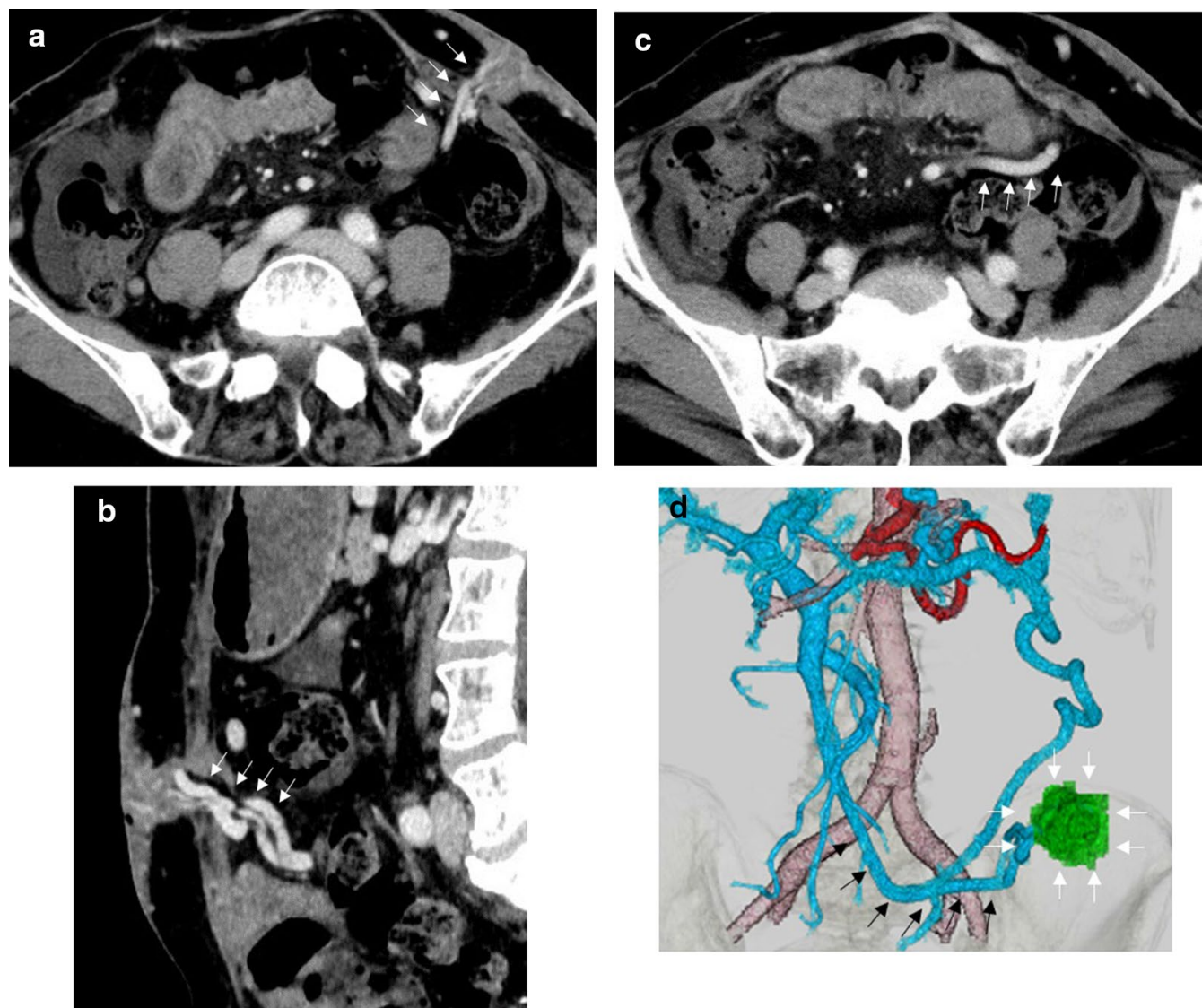

Fig. 2 Abdominal CT imaging. a (horizontal slice), b (sagittal slice) Ectopic varices and collateral vessels at the ileal conduit stoma (arrow). cThe varices were fed by superior mesenteric vein (arrow). d Three-dimensional reconstruction showed the ileal conduit stomal varices (white arrow) fed by the superior mesenteric vein (black arrow)

She was then discharged from our hospital. She has had no bleeding from her ileal conduit stoma, and no worsening of her portal thrombosis or liver function for 1 year after the hybrid surgery.

\section{Discussion}

Hemorrhage from gastrointestinal variceal bleeding is the most serious and life-threatening complication among patients with $\mathrm{PH}[1-3]$. Typically, gastrointestinal varices are located at the gastroesophageal junction; varices located outside the esophagus and stomach are, therefore, considered ectopic varices. Ectopic variceal bleeding is rare, and is an uncommon cause of gastrointestinal hemorrhage in portal hypertensive patients; it is difficult to diagnose and treat [2]. ICSVs are a rarely reported type of ectopic varices in patients who develop $\mathrm{PH}$ after urinary diversion [14-18].

To our knowledge, hybrid surgery for ICSV has never been reported before. Hybrid surgery that combines angiography during surgery provides much information to complete the shunt surgery, especially in cases with history of poly-surgery, obesity and the complicated vascular anatomy of ICSV. Here we report a case of ICSV, for which conventional treatment would have been challenging because of repeated massive bleeding over a long time, but was successfully treated with hybrid surgery.

PH is caused by liver cirrhosis, which may be caused by chronic hepatitis $\mathrm{B}$ or $\mathrm{C}$, alcoholic hepatitis, nonalcoholic steatohepatitis, autoimmune hepatitis, or idiopathic PH [19]. In this case, the patients had no history of liver disease, so liver damage induced by oxaliplatinbased chemotherapy for CRC is thought to be the cause of her PH. Oxaliplatin-based chemotherapy is a standard systemic chemotherapy for advanced unresectable recurrent CRC $[4,20]$. However, liver injury due to sinusoidal obstruction syndrome is a reported side effect of oxaliplatin $[6,7]$. Details of the relationship between duration of oxaliplatin administration and the onset of liver damage are unclear, but liver damage apparently becomes more likely as the number of chemotherapy courses increase; therefore, more careful follow-up is required for oxaliplatin patients, especially those treated for six courses 

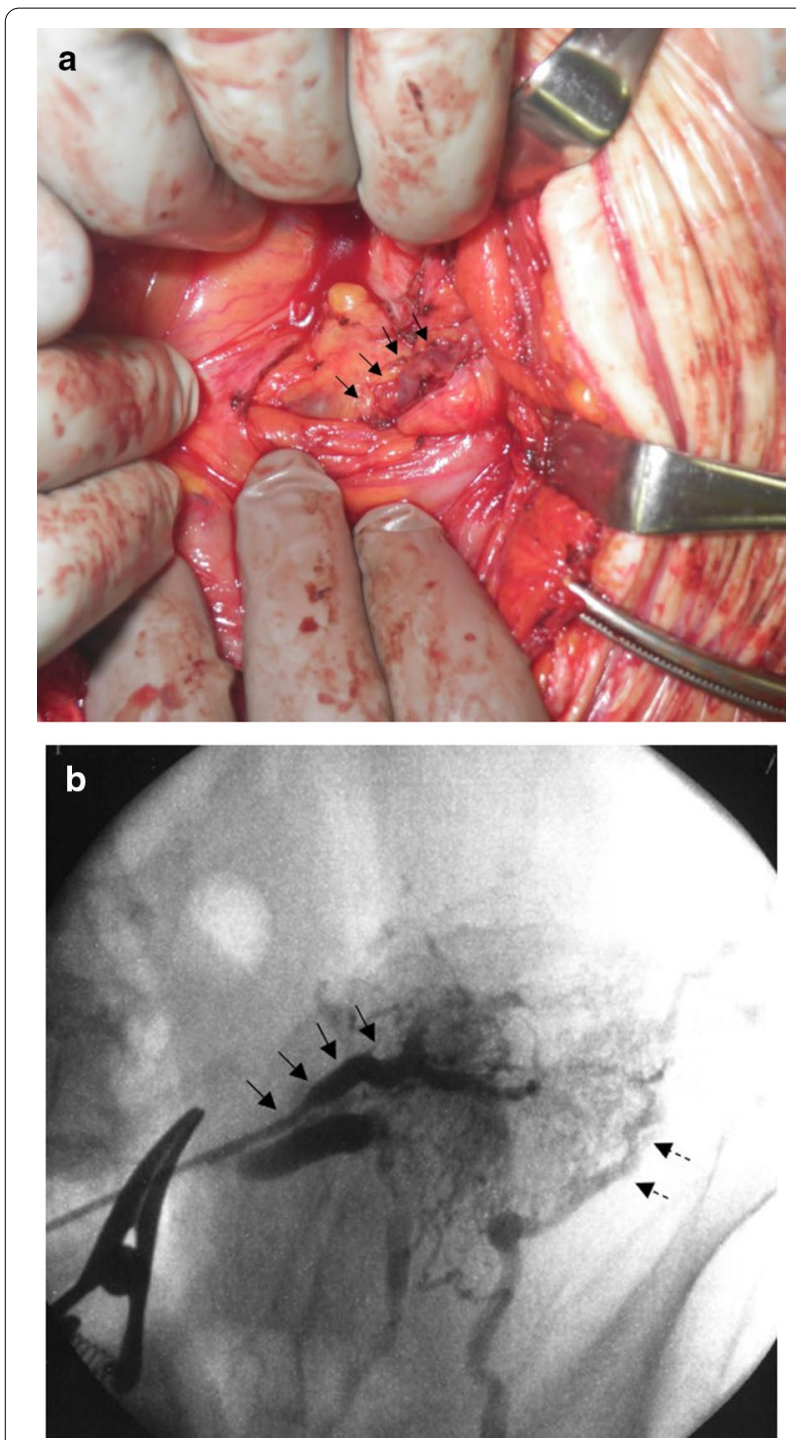

Fig. 3 a After dissecting the dense peritoneal adhesion, we found dilated and tortuous vessels in the mesentery of small intestine. b Angiography showed sufficient opacification of stomal varices, including the two SMV feeding veins (arrow), which were numerous cutaneous veins around ileal conduit stoma that communicated the left femoral vein (arrow dotted)

or more [21, 22]. This patient developed splenomegaly, thrombocytopenia, and collateral formation around the time of her 9th mFOLFOX6 plus bevacizumab course before her second surgery.

Ectopic varices in the small intestine and stoma are usually associated with adhesions to the abdominal wall, resulting from prior operations, so accurate diagnosis is difficult, and often is not found until well after onset. Recent advances in multi-detector row CT (MDCT) have made detection of ectopic varices easier [23, 24]. Three-dimensional angiography with MDCT is useful

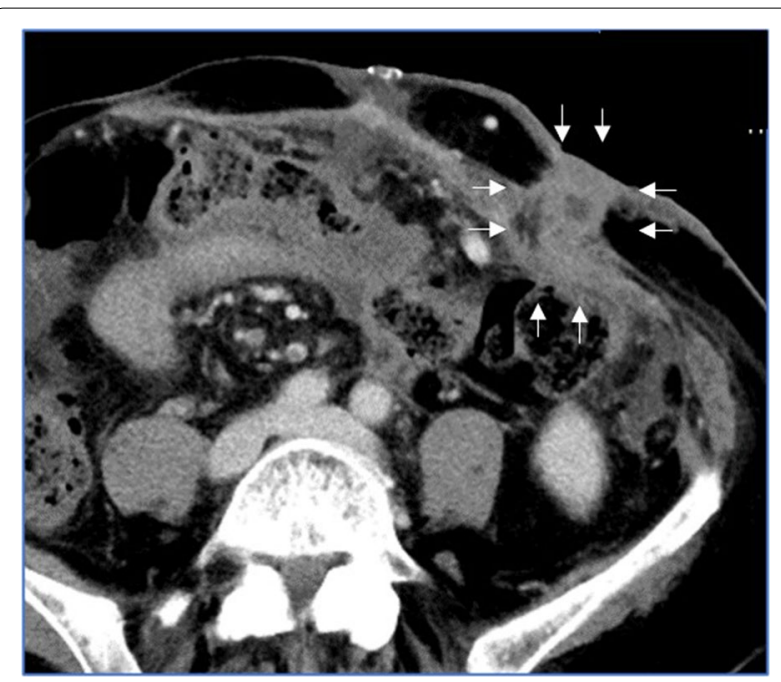

Fig. 4 Abdominal CT imaging 7 days after the hybrid surgery. The feeding veins were occluded and the ileal conduit stomal varices had disappeared

for identifying collateral circulation of ectopic varices and determining optimal treatment methods. In this case, MDCT showed the ICSV was fed by the SMV and drained into the left femoral vein. Patients with gastrointestinal bleeding and $\mathrm{PH}$ should receive MDCT to diagnose ectopic variceal bleeding, especially for patients with histories of prior surgery.

Methods to treat ectopic intestinal varices, including TIPS, BRTO, surgical treatment and medical treatment, have been widely reported, but the standard treatment has not been established yet. Treatment for ectopic varices should be determined after diagnosing the location and clinical symptoms, and by fully considering the risks and benefits of the treatment method. According to previous reports, nine cases of ICSV associated with portal hypertension after urinary diversion have been reported. In eight of all cases, endovascular treatment was performed and most of the endovascular treatment was TIPS [15, 17, 25-31]. TIPS-which uses a percutaneous catheter to create a short circuit between the portal and hepatic veins in the liver-has been widely used in Western countries for reducing the pressure of portal vein as a treatment for $\mathrm{PH}$, but seems to be unsatisfactory for ectopic varices, with a reported $21-37 \%$ rebleeding rate $[8,32]$, arguably because ectopic varices are formed as a part of portosystemic shunt, so the pressure of portal vein is mostly lower in patients with ectopic varices than in those with esophageal varices [10,33]. TIPS may also cause complications, such as exacerbation of hepatic encephalopathy and stent occlusion. BRTO has been widely used to treat gastrointestinal varices and hepatic encephalopathies associated with portosystemic shunts 
[9-11, 32, 33], and is minimally invasive, but may cause esophageal varices to develop or worsen, owing to posttreatment increase in portal pressure, and have difficulty in cannulating the variceal drainage veins. In this case, the ICSV drainage vein was narrow and meandering, which made retrograde cannulation difficult. We, therefore, selected hybrid surgery to treat the ICSV, identifying the variceal feeding vessels and obliterating the ethanolamine oleate with iopamidol while blocking venous flow to the stomal varices. If no adhesions are found around the ileum, trans-ileocecal antegrade obliteration with a balloon catheter is an option for obliterating the varices.

\section{Conclusion}

In conclusion, therapeutic strategy of ectopic varices should be based on their precise vascular anatomy to avoid fail to obliterate or prevent recurrence of ectopic varices. Hybrid surgery that combines angiography provides the information about the vascular anatomy of ectopic varices including the collateral circulation intraoperatively and can be an alternative treatment of ectopic varices such as the ICSV.

\begin{abstract}
Abbreviations
PH: Portal hypertension; CRC: Colorectal cancer; ICSVs: Ileal conduit stomal varices; SMV: Superior mesenteric vein; TIPS: Trans-jugular intrahepatic portosystemic shunt; BRTO: Balloon-occluded retrograde transvenous obliteration; CT: Contrast-enhanced computed tomography; MDCT: Multi-detector row CT.
\end{abstract}

\section{Acknowledgements}

We thank Marla Brunker from Edanz Group (www.edanzediting.com/ac), for assisting in the preparation of the manuscript.

\section{Authors' contributions}

$H U, H K$, TK and MS performed the surgery and were responsible for the perioperative management on the patient. $\mathrm{HU}$ and $\mathrm{HK}$ participated in the drafting of the manuscript. MO, YM, KS, MM and YT helped to draft the manuscript. All authors read and approved the final manuscript.

\section{Funding}

This research received no specific grant from any funding agency in the pubic, commercial, or not-for-profit sectors.

\section{Availability of data and materials}

Data sharing is not applicable to this article, as no datasets were generated or analyzed during the current study.

\section{Ethics approval and consent to participate}

The present study was conducted in this article, as no funding agency in the public, commercial, or not-for-profit sectors.

\section{Consent for publication}

Written informed consent was obtained from the patient for the publication of this case report and any accompanying images.

\section{Competing interests}

The authors declare that they have no competing interests.

\section{Author details}

1 Department of Gastroenterological Surgery, National Hospital Organization Kyushu Cancer Center, Notame 3-1-1, Minami-ku, Fukuoka 811-1395, Japan. ${ }^{2}$ Clinical Research Institute and Department of Surgery, National
Hospital Organization Beppu Medical Center, 1473 Uchikamado, Beppu, Oita 874-0011, Japan. ${ }^{3}$ Department of Hepatobiliary-Pancreatic Surgery, National Hospital Organization Kyushu Cancer Center, Notame 3-1-1, Minami-ku, Fukuoka 811-1395, Japan.

Received: 27 July 2020 Accepted: 21 September 2020

Published online: 29 September 2020

\section{References}

1. D'Amico G, Pagliaro L, Bosch J. The treatment of portal hypertension: a meta-analytic review. Hepatology. 1995;22:332-54.

2. Lebrec D, Benhamou JP. Ectopic varices in portal hypertension. Clin Gastroenterol. 1985;14(1):105-21.

3. Biecker E. Portal hypertension and gastrointestinal bleeding: diagnosis, prevention and management. World J Gastroenterol. 2013;19(31):5035-50.

4. André T, Boni C, Mounedji-Boudiaf L, Navarro M, Tabernero J, Hickish T, Topham C, Zaninelli M, Clingan P, Bridgewater J, Tabah-Fisch I, Gramont A, Multicenter International Study of Oxaliplatin/5-Fluorouracil/Leucovorin in the Adjuvant Treatment of Colon Cancer (MOSAIC) Investigators. Oxaliplatin, fluorouracil, and leucovorin as adjuvant treatment for colon cancer. N Engl J Med. 2004;350:2343-51.

5. Kuebler JP, Wieand HS, O'Connell MJ, Smith RE, Colangelo LH, Yothers G, Petrelli NJ, Findlay MP, Seay TE, Atkins JN, Zapas JL, Goodwin JW, Fehrenbacher L, Ramanathan RK, Conley BA, Flynn PJ, Soori G, Colman LK, Levine EA, Lanier KS, Wolmark N. Oxaliplatin combined with weekly bolus fluorouracil and leucovorin as surgical adjuvant chemotherapy for stage $\|$ and III colon cancer: results from NSABP C-07. J Clin Oncol. 2007;25:2198-204.

6. Brandt LR, Audard V, Sartoretti P, Roth AD, Brezault C, Charpentier ML, Dousset B, Morel P, Soubrane O, Chaussade S, Mentha G, Terris B. Severe hepatic sinusoidal obstruction associated with oxaliplatin-based chemotherapy in patients with metastatic CRC. Ann Oncol. 2004;15:460-6.

7. Ribero D, Wang H, Donadon M, Zorzi D, Thomas MB, Eng C, Chang DZ, Curley SA, Abdalla EK, Ellis LM, Vauthey JN. Bevacizumab improves pathologic response and protects against hepatic injury in patients treated with oxaliplatin- based chemotherapy for colorectal liver metastases. Cancer. 2007;110:2761-7.

8. Vidal V, Joly L, Perreault P, Bouchard L, Lafortune M, Layrargues GP. Usefulness of transjugular intrahepatic portosystemic shunt in the management of bleeding ectopic varices in cirrhotic patients. Cardiovasc Intervent Radiol. 2006:29:216-9.

9. Kanagawa H, Mima S, Kouyama H, Gotoh K, Uchida K, Okuda K. Treatment of gastric fundal varices by balloon-occluded retrograde transvenous obliteration. J Gastroenterol Hepatol. 1996;11:51-8.

10. Hashimoto N, Akahoshi T, Yoshida D, Kinjo N, Konishi K, Uehara H, Nagao Y, Kawanaka H, Tomikawa M, Maehara Y. The efficacy of balloon-occluded retrograde transvenous obliteration on small intestinal variceal bleeding. Surgery. 2010;148:145-50.

11. Kawanaka H, Akahoshi T, Nagao Y, Kinjo N, Yoshida D, Matsumoto Y, Harimoto N, Itoh S, Yoshizumi T, Maehara Y. Customization of laparoscopic gastric devascularization and splenectomy for gastric varices based on CT vascular anatomy. Surg Endosc. 2018;32:114-26.

12. Kawanaka H, Akahoshi T, Kinjo N, Konishi K, Yoshida D, Anegawa G, Yamaguchi S, Uehara H, Hashimoto N, Tsutsumi N, Tomikawa M, Maehara Y. Impact of antithrombin III concentrates on portal vein thrombosis after splenectomy in patients with liver cirrhosis and hypersplenism. Ann Surg. 2010;251:76-83.

13. Kawanaka H, Akahoshi T, Ito S, Iguchi T, Harimoto N, Uchiyama H, Yoshizumi T, Shirabe K, Takenaka K, Maehara Y. Optimizing risk stratification in portal vein thrombosis after splenectomy and its primary prophylaxis with antithrombin III concentrates and danaparoid sodium in liver cirrhosis with portal hypertension. J Am Coll Surg. 2014;219:865-74.

14. Macedo TA, Andrews JC, Kamath PS. Ectopic varices in the gastrointestinal tract: short- and long-term outcomes of percutaneous therapy. Cardiovasc Intervent Radiol. 2005;28:178-84.

15. Naidu SG, Castle EP, Kriegshauser JS, Huettl EA. Direct percutaneous embolization of bleeding stomal varices. Cardiovasc Intervent Radiol. 2010;33(1):201-4. 
16. Oderda M, Mondino P, Lucca I, Fiorito C, Gillo A, Zitella A, Greco A, Tizzani A, Gontero P. Fatal haematuria in a patient with an orthotopic neobladder and chronic liver failure. Urol Int. 2009;83(3):368-9.

17. Onishi Y, Kimura H, Kanagaki M, Oka S, Fukumoto G, Otani T, Matsubara N, Kawabata K, Yasufuku Y, Yamada Y. Successful embolization of ileal conduit stomal varices with $\mathrm{N}$-butyl cyanoacrylate via a recanalized paraumbilical vein. Radiol Case Rep. 2018;13:1130-2.

18. Tsao GG, Abraldes JG, Berzigotti A, Bosch J. Portal hypertensive bleeding in cirrhosis: risk stratification, diagnosis, and management: 2016 practice guidance by the American Association for the study of liver diseases. Hepatology. 2017;65(1):310-35.

19. Yamada Y, Takahari D, Matsumoto H, Baba H, Nakamura M, Yoshida K, Yoshida M, Iwamoto S, Shimada K, Komatsu Y, Sasaki Y, Satoh T, Takahashi K, Mishima H, Muro K, Watanabe M, Sakata Y, Morita S, Shimada Y, Sugihara K. Leucovorin, fluorouracil, and oxaliplatin plus bevacizumab versus S-1 and oxaliplatin plus bevacizumab in patients with metastatic colorectal cancer (SOFT): an open-label, non-inferiority, randomised phase 3 trial. Lancet Oncol. 2013;14(13):1278-86.

20. Nakano H, Oussoultzoglou E, Rosso E, Casnedi S, Chenard-Neu MP, Dufour $\mathrm{P}$, Bachellier $\mathrm{P}$, Jaeck D. Sinusoidal injury increases morbidity after major hepatectomy in patients with colorectal liver metastases receiving preoperative chemotherapy. Ann Surg. 2008;247:118-24.

21. Karoui M, Penna C, Amin-Hashem M, Mitry E, Benoist S, Franc B, Rougier $\mathrm{P}$, Nordlinger $\mathrm{B}$. Influence of preoperative chemotherapy on the risk of major hepatectomy for colorectal liver metastases. Ann Surg. 2006;243:1-7

22. Willmann JK, Weishaupt D, Bohm T, Pfammatter T, Seifert B, Marincek B, Bauerfeind P. Detection of submucosal gastric fundal varices with multidetector row CT angiography. Gut. 2003;52:886-92.

23. Kakizaki S, Ishikawa T, Koyama Y, Yamada H, Kobayashi R, Sohara N, Otsuka T, Takagi H, Mori M. Primary biliary cirrhosis complicated with sigmoid colonic varices: the usefulness of computed tomographic angiography. Abdom Imaging. 2003:28:831-4.

24. Kochar N, Tripathi D, McAvoy NC, Ireland H, Redhead DN, Hayes PC. Bleeding ectopic varices in cirrhosis: the role of transjugular intrahepatic portosystemic stent shunts. Aliment Pharmacol Ther. 2008;28:294-303.
25. Chavez DR, Snyder PM, Juravsky LI, Heaney JA. Recurrent ileal conduit hemorrhage in an elderly cirrhotic man. J Urol. 1994;152(3):951-3.

26. Lashley DB, Saxon RR, Fuchs EF, Chin DH, Lowe BA. Bleeding ileal conduit stomal varices: diagnosis and management using transjugular transhepatic angiography and embolization. Urology. 1997;50(4):612-4.

27. Soret R, Goullet E, Bonnal JL, Dharancy S, Paris JC, Mauroy B. Recurrent peri-stomal varix hemorrhage after diversion using the Bricker's technique. Progres en urologie: journal de I'Association francaise d'urologie et de la Societe francaise d'urologie. 2001;11(2):310-3.

28. Yao DH, Luo XF, Zhou B, Li X. Ileal conduit stomal variceal bleeding managed by endovascular embolization. World J Gastroenterol. 2013;19(44):8156-9.

29. Tan ST. Sclerotherapy for rare bleeding stomal varices after ileal conduit urinary diversion: an effective and noninvasive method. Scott Med J. 2014;59(4):e5-e7.

30. Dal Moro F. Long-delayed gross hematuria due to portal hypertension in an alcoholic cirrhotic patient with ileal conduit urinary diversion. Ann Hepatol. 2014;13(6):830-1.

31. Gowda SN, Sethi P, Motapothula U. Peristomal variceal hemorrhage at the ileal conduit site due to extrahepatic portosystemic shunt. Indian J Urol. 2020;36(2):130-2

32. Akahoshi T, Hashizume M, Tomikawa M, Kawanaka H, Yamaguchi S, Konishi K, Kinjo N, Maehara Y. Long-term results of balloon-occluded retrograde transvenous obliteration for gastric variceal bleeding and risky gastric varices: a 10-year experience. J Gastroenterol Hepatol. 2008;23:1702-9.

33. Kinjo N, Kawanaka H, Tomikawa M, Taketomi A, Soejima Y, Yoshizumi T, Yamaguchi S, Yoshida D, Maehara Y. B-RTO for ectopic variceal bleeding after living donor liver transplantation. Hepatogastroenterology. 2008;55:241-3

\section{Publisher's Note}

Springer Nature remains neutral with regard to jurisdictional claims in published maps and institutional affiliations.

\section{Submit your manuscript to a SpringerOpen ${ }^{\circ}$ journal and benefit from:}

- Convenient online submission

- Rigorous peer review

- Open access: articles freely available online

- High visibility within the field

Retaining the copyright to your article

Submit your next manuscript at springeropen.com 